\title{
Stem cells: sources and therapies
}

\author{
Manuela Monti ${ }^{1}{ }^{*}$, Cesare Perotti ${ }^{2}$, Claudia Del Fante ${ }^{2}$, Marila Cervio ${ }^{2}$, Carlo Alberto Redi ${ }^{1}$ \\ Fondazione IRCCS Policlinico San Matteo, Pavia (Italia) \\ ${ }^{1}$ Center for regenerative medicine, San Matteo Foundation for Research, Hospitalization and Health Care, Viale Camillo Golgi, 19 - 27100 Pavia (Italy) \\ ${ }^{2}$ Immunohematological Unit, San Matteo Foundation for research, hospitalization and health care, Viale Camillo Golgi, 19 - 27100 Pavia (Italy)
}

\begin{abstract}
The historical, lexical and conceptual issues embedded in stem cell biology are reviewed from technical, ethical, philosophical, judicial, clinical, economic and biopolitical perspectives. The mechanisms assigning the simultaneous capacity to self-renew and to differentiate to stem cells (immortal template DNA and asymmetric division) are evaluated in the light of the niche hypothesis for the stemness state. The induction of cell pluripotency and the different stem cells sources are presented (embryonic, adult and cord blood). We highlight the embryonic and adult stem cell properties and possible therapies while we emphasize the particular scientific and social values of cord blood donation to set up cord blood banks. The current scientific and legal frameworks of cord blood banks are reviewed at an international level as well as allogenic, dedicated and autologous donations. The expectations and the challenges in relation to present-day targeted diseases like diabetes mellitus type I, Parkinson's disease and myocardial infarction are evaluated in the light of the cellular therapies for regenerative medicine.
\end{abstract}

Key words: embryonic stem cell; adult stem cell; pluripotency; induced pluripotent stem cells; umbilical cord blood; spinal cord stroke; Parkinson' disease.

\section{STEM CELL HISTORY: FROM PAPPENHEIM TO MICRORNAs}

To understand the range of stem cell (SC) biology in technical, ethical, philosophical, judicial, clinical, economic and biopolitical issues, two pre-requisites must be clarified: 1) the derivation of the term "stem cell" or better, its root "staminal" and 2) anatomic SC sources. This is necessary for the psychological implications behind the daily use of scientific terms: for example, the colloquial use of the term "life". While appearing to have a scientific meaning, it actually refers to the experience spectrum of everyone that has lived.

Regarding the derivation of the words stem and staminal, only two contributions explain it. Ramalho-Santos and Willenbring (2007) suggested that: "One would be tempted to assume that the term stem cell has some relation to the term "meristem" because meristems are the stem cell compartments of plants." The term meristem was first used by the botanist Karl Nägeli, born in Switzerland, describing the areas of continual cell division in a plant (Nägeli, 1858). He derived the term from the Greek "meristos" and the suffix "-em" (as in "phloem" or "xylem").

Since the adjective staminalis, $-e$ did not exist in Latin, we suggested (Monti and Redi, 2011a) the neutral noun stamen, -inis being the basis of the neo-Latin word "staminal", which was coined in an English-speaking scientific environment. Stamen indicates the warp of the cloth and metaphorically suggests "the fiber of life" with the idea of a "grounding" entity, which is the founding "stem cell".

SCs are then defined by their double capability to simultaneously perform two distinct processes: self-renewal and differentiation. The phenomenon that ensures this capacity is called "asymmetric division", but there is no agreement on the mechanism that sustains it. Another hypothesis, focused on the "immortal DNA strand", suggests that the daughter cell inheriting the old "template" strand keeps the stem capacity, while its sister cell inheriting the new DNA strand will undergo differentiation (Cairns, 1975; 2002; 2006). Notably, this hypothesis can account for the origin of cancer stem cells (CSC) since the mutations will continuously accumulate in the newly synthesized DNA strands that are always inherited by the differentiative-committed cell reaching the neoplastic (stemness) condition due to the inactivation of tumor suppressor genes (Cairns, 2006; Rando, 2007). Supporting this view, Reya and Clevers (2005) showed that different kind of tumors share the deregulation of the Wnt signaling network that is able to activate the self-renewal capacity. The European group "Migrating Cancer Stem Cells" (www.mcscs.eu), led by Riccardo Fodde, is continuously updating the CSC biology field. Recently, however, the hypothesis of the immortal template DNA was questioned by the evidence that it does not apply to intestinal epithelial SCs (Escobar et al., 2011).

An alternative is the SC hub-niche hypothesis presented by Schofield (1978). It is based on studies in the vertebrate's hematopoietic system and was corroborated by the Caenorhabditis elegans germ cell development (Kimble and White, 1981) and research with the Drosophila melanogaster ovary (Kiger et al., 2001; Tulina and Matunis, 2001; Fuller and Spradling, 2007). Several reviews illustrated how the SC niche represents a paradigmatic concept in SC biology (Scheres, 2007; Jones and Wagers, 2008; Knoblich, 2008; Morrison and Spradling, 2008). Proximal signals (cell surface molecules) as well as distal ones (secreted molecules) act in a specialized anatomical microenvironment (the hub-niche) where they control cell proliferation and differentiation. Whatsoever the explanation, the medical community has an intense interest in using SCs for cell replacement therapies in tissues that have been damaged by aging, trauma or specific pathologies. 
As for the SC sources: at first it was thought, naively, that only a few tissues posses SCs: blood, intestinal epithelia, bones, skin. Now we know that they can be found in any tissue of the body, surprisingly in the pulp of deciduous teeth (Gronthos et al., 2000), amniotic fluid (De Coppi et al., 2007) and breast milk (Cregan et al., 2007). Nerve tissue was believed to be completely differentiated, but it presents SCs, even within 18 hours after death. In mammals, all phases of preimplantation embryo development yield embryonic SCs (ESC). After implantation, the embryo affords somatic SCs (SSC), which unfortunately are also called "adult". Nearly $10^{15}$ ESCs in the human are pluripotent; a few ESCs of the early embryo are totipotent: only these are able to produce every type of body cell in any number.

The restricted SSCs are multipotent when they give rise to more than one cell type pertaining to a specific cell lineage. More restriction happens later on in development, and SSCs become only unipotent when they produce just a single cell type.

Until the beginning of the 1950s, the existence of SCs was conjectural. After the Second World War, autoradiography introduced time as the fourth dimension to histological investigation, along with the conversion of the nuclear energy physics into biological application. French-Canadians took the opportunity to follow the movements of labeled isotopes in time and thus discovered the renewing male germ cells (Leblond and Clermont, 1952) and the SCs at the base of the intestinal villi. From that moment on, there was fast and furious flourishing of SC discoveries that have lead us to revolutionize the SC concept. Examples were the induction of stemness in a terminally differentiated cell (Yamanaka, 2009) and the new way of looking at cancer stem cells (CSC; www.mcscs.eu). This important field of research is still fascinating in retrospect. Some SC bibliographic masterpieces are quite instructive for those entering the field. We recommend the 2006 EMBO summary Stem Cell Research - status, prospects, prerequisites (www.embo. org/index.php). This is still a valid document introducing SC biology and all problems related to what is undoubtedly considered the hottest topic in biology and medicine nowadays. The journal Nature offers a website devoted to SCs, which is constantly updated and particularly instructive (www.nature. com/stemcells/index.html). We also note the drawings by Artur Pappenheim who lived 13 Dec 1870 - 31 Dec 1916 (Dinser 2001). He unraveled the differentiation of hematopoietic cells while working at the Virchow Pathological Institute in Berlin (see Fig. 2 in Maehle, 2011). This is especially interesting when compared to the present-day view about the microRNA modulation in the hematopoietic lineage (Chen et al., 2004; Kluivert et al., 2006). This comparison teaches the lesson that sometimes, in science, it is reasonable and fruitful to believe in something invisible! The mammalian egg for example was not discovered until Karl Ernst von Baer found it in 1827. But it was supposed to exist already during the time of Johann van Horne (1621 - 1670), Niels Stensen (1638 - 1686) and Reignier de Graaf (1641 - 1673). Actually, we know perfectly the microRNAs, which control self-renewal and cell differentiation in the hematological system (Chen et al., 2004; Kluivert et al., 2006). Their identification is due to a fundamental change of biology from a historical (ontological) science to a hard science, from the description to the synthesis of life. Now we can biotechnologically produce these desired cells, thus - there will be blood! (Durand and Zon, 2012; literature quoted there).

\section{STEM CELL TYPES: EMBRYONIC AND SOMATIC}

ES cells have been first derived in the mouse by Martin Evans and Matthew Kaufman (1981) from the Dept. of Genetics, Cambridge University, UK, and by Gail R. Martin (1981) from the Dept. of Anatomy, University of California, San Francisco, who coined the term "embryonic stem cell". Later on, such cells were isolated from blastocysts in primates and humans (Thomson et al., 1998). These projects have been funded by large private pharmacy corporations like Geron (Menlo Park, California, USA). The USA Federal government under President George W. Bush's leadership never supported research with human embryos. However, President Barak Obama is promoting such studies, and new ES lines have been derived and are now freely available to the scientific community (http:/ / stemcells.nih.gov/ registry).

The primordial germ cells (PGC) appear at the 1st and 3rd developmental week in mouse and human, respectively. Once isolated from the embryo, these cells can multiply giving rise to pluripotent embryonic germ cells (EG, Shamblott et al., 1998). Anyway, difficult and time-consuming isolation restrains their use in therapy.

ES cells can be obtained from embryos. This is a legal practice where the ethical debate on the embryo status has reached a consensus either on a pragmatic-utilitarian view (Australia) or on an ideological-religious view (Singapore, Taiwan, Israel). In these countries, embryos come from in vitro fertilization clinics after the procedures have granted a baby. Both partners have to sign an informed consent form agreeing to donate embryos for ESC derivation. In other countries like Brazil, Spain and the UK, a special authority, like the Human Fertility and Embryology Authority (HFEA; www. hfea.gov.uk) rules on research applications. The green light for the derivation of ESC lines is given very rarely. The donor embryos must be destroyed mandatorily before the end of the second developmental week. In many more countries (for example, Austria, Germany, Ireland, Italy), embryos left after IVF have to be cryo-preserved. The international situation, the ethical issues and the philosophical themes are broadly discussed in "Biopolitics of the frozen embryos" by Monti and Redi (2011b).

\section{INDUCTION OF PLURIPOTENCY: THE EGG AS THE REPRO- GRAMMOME}

Embryos can be created de novo when nuclei of terminally differentiated cells are transferred into de-nucleated oocytes. The oocyte cytoplast enforces genetic reprogramming of the received nucleus, which acquires the embryonic developmental programme. Nuclear transfer is the pivotal technique in the cloning procedure with animals. The first success was Dolly the sheep (Wilmut et al., 1997). Even though this did not result from a proper procedure of nuclear transfer, Cumulina, the first cloned mouse, clearly did at least (Wakayama et al., 1998).

If the development of the composed embryo is stopped at the first mitotic divisions, ESCs can be derived from its inner cell masses. This fact opens the possibility of producing autologous SCs on demand for personalized medical treatments. Unfortunately, this theoretical possibility gave rise to the term therapeutic cloning. The term is often used, but should be avoided, since it calls to mind unacceptable practices, e.g., human cloning (Solter, 2002). 
Nuclear transfer techniques show the capacity of the oocyte cytoplasm to induce activation of the stemness genes, but the responsible substances and their mechanism still remain unknown. Seminal studies by Hans Spemann and Hilde Mangold proved a cytoplast's capacity to induce re-acquisition of the stemness status, and for his discovery of the organizer effect in embryonic development, Spemann won the Nobel Prize 1935 (www.nobelprize.org).

Recent studies by Sir John Gurdon and colleagues worked out that the reprogramming process replaces somatic proteins by oocyte polypeptides and includes DNA demethylation and histone modification. Since these reactions obey a chronological order, the Gurdon group supports a deterministic view for the phenomenon (Jullien et al., 2011, especially Figures 1-4). Thus, the authors face the prevailing stochastic idea that, however, better justifies the very small yields of the process.

Extracts from oocyte cytoplasts, when added to differentiated cells in culture, will probably hugely increase the yield of reprogrammed cells. This promising consideration justifies the efforts put forward by the scientific community to find the best strategy. A "natural" approach will use denucleated oocytes or ESCs, whereas an artificial way will lead to the synthesis of molecules showing reprogramming capacity (Byrne, 2011). Using a cytoplastic strategy, it was possible to turn fibroblasts into ES-like cells by "growing" them in cytoplast extracts from mouse oocytes. Considering $\approx 0.01-0.1 \%$ efficiency, the yield of reprogrammed cells was good (Neri et al., 2007). A cocktail of the essential substances should theoretically be able to erase the epigenetic imprinting of the differentiated starting cells and to switch on the stemness network. It seems reasonable that stemness does not depend from a single gene, but hinge on a genetic cascade. The theoretical premises came forward from the group of Helen Blau who showed that a defined and specific methylation status of Oct-4 and Nanog genes is necessary to get a stemness status (Palermo et al., 2009). Recently, Michele Boiani and colleagues restricted the number of the candidate factors of the "reprogrammome" to 28 polypeptides (Pfeiffer et al., 2011).

\section{INDUCED PLURIPOTENT STEM CELLS (iPS)}

Some genes play a master role in activation and maintenance of the regulatory stemness networks. Their ectopic expression opens a "direct" route to pluripotency in target cells. The feasibility of this strategy was proved at Kyoto University by transfection of the four stemness genes Oct4, Sox2, c-myc and Klf4 into terminally differentiated fibroblasts. Takahashi and Yamanaka (2006) used retroviruses that supported the induction of pluripotency in a very small fraction of the fibroblasts (only $0.001-0.01 \%$ efficiency). All the reprogramming techniques for induced pluripotent stem cells (iPS) have still low efficiency, due to several reasons explained by Shinya Yamanaka (2009). However, his pioneering study allowed researchers to reduce, step by step, the required genes to one, Oct4, and to obtain high rates of reprogramming (Giorgetti et al., 2009; Kim 2009). Now we conceive that the elusive cytoplast substances are made of just some of the proteic products of the master stemness genes (e.g., Oct4, Sox2, Nanog).

The data are of social importance, because they testify to the good attitude and responsibility of the scientific community in public problems. The iPS cells liberate especially
Catholics from the Roman disagreement on the use of ESCs. The iPS cells provide a positive perspective in science-society relation.

The theoretic background and the conceptual derivation of the physiological principles of cellular reprogramming have been reviewed by Thomas Graf and Tariq Enver (2009). Wolfgang Reik and colleagues presented a similar model within a Waddington's epigenetic landscape (Hemberger et al., 2009).

Ideal approaches avoid the use of foreign DNAs in reprogramming. This objective was aimed at by the use of chemicals or by biophysical stimuli at the Scripps Research Institute (La Jolla, California). The group of Sheng Ding produced iPS cells using purified proteins, which were derived from the four Yamanaka's genes (Xu et al., 2008; Li et al., 2009). Their protein mix contained valproic acid (a histone deacetylase inhibitor), synthetic small molecules and natural products, which are able to bind nuclear receptors, histoneand DNA-modifying enzymes, protein kinases and signaling molecules.

To get the story on promises and reality of iPS cells updated, see the Special Insight on regenerative medicine in Nature 453:301 (2008), Stadtfeld and Hochedlinger (2010), as well as Hayden (2011). After all, the Nature web focus is devoted to stem cells nowadays (www.nature.com/focus/ stemcells).

\section{STEM CELL SOURCES}

A vast body of literature is devoted to the SC derivation from almost every organ (for information, readers can refer to the web sites mentioned above). In addition, we have acquired the ability to produce several cell types from the SSC isolated from different tissues of adults, fetuses and the umbilical cord blood (CB). SC isolated from preimplantation embryos only now entering the preclinical trials steps due to the necessary caution in their use (their clonogenic capacity can lead to tumors) and for the ethical and legal considerations on the embryo status (Monti and Redi, 2011b). No doubt, ES are a need for the scientific community, but actually for other uses than for therapies; in other words, we need them to advance our knowledge on the very first embryo developmental steps and to shorten the time of toxicological and pharmacological tests so that translational medicine can take profit of the iPS' ability to "draw in a test tube" the diseases. However, quite frequently the ethical concerns on the ES derivation from embryos (either from frozen or de novo created embryos) focus the debate on the attempts put forwards to accommodate this problem (Monti and Redi, 2011b) thus diverting our attention from alternative SC sources that intrinsically resolve the ethical concerns: in other words, the SSC that can be obtained from the umbilical cord blood (CB). Here we would like to draw the reader's attention on this partly neglected SC source in the hope to boost the creation of public CB banks.

\section{STEM CELLS FROM UMBILICAL CORD BLOOD}

Ethical concern about ESC derivation from embryos guides our attention to alternative sources. The cord blood (CB), also known as placental blood, contains SSCs, which are not subject to ideological restrictions. In 1988, Eliane Gluckman conducted the first successful transplantation of SCs from 
CB. The recipient was a young patient suffering from Fanconi anemia, a rare congenital blood disease. The success invalidated the idea that hematopoietic SCs can be exclusively derived from bone marrow, and further that only these cells can be used for transplantation. Three research groups have combined their different skills to overcome the prevailing skepticism. Arleen Auerbach (Rockefeller University, New York) devised a reliable method for the prenatal diagnosis of Fanconi anemia. Hal Broxmeyer (Indiana University) deeply studied the characteristics of the CB hematopoietic SCs: their sufficient number and clonogenic potential to repopulate bone marrow. After all, Eliane Gluckman (Hôpital Saint-Louis, Paris University VII) devised the pre-transplant conditioning by reduced chemotherapy, which allowed the engraftment of CB SCs. The prenatal diagnosis had proved the CB SCs of the young patient and of his brother being healthy and compatible. CB was collected after birth, cryo-preserved at $-180^{\circ} \mathrm{C}$, and infused after rapid thawing. The first signs of the transplanted cells appeared twenty-two days later and finally brought complete hematologic and immunologic reconstitution. The patient is alive and in good health twenty years after the transplant. This exciting experience evoked many scientific, organizational and ethical questions.

Is the $\mathrm{CB}$ collection safe for both the mother and the baby? Does the volume of one umbilical cord $(60-120 \mathrm{ml})$ contain sufficient SCs to ensure success of a transplant? Does the "contamination" of CB with maternal cells cause severe immune responses in the recipient? Can we obviate the dreaded graft versus host reaction? Can patients with onco-hematological diseases, such as leukemia, recover after transplant? Are CB SCs different from SSCs concerning immunological properties and the ability to repopulate bone marrow? What are the criteria for collecting, storing and monitoring samples of $\mathrm{CB}$ ? Is the therapeutic benefit worth the preceding efforts?

In recent years, the worldwide cooperation of institutions yielded answers to all these questions. Eurocord, funded by the European Union, provides an international platform specialized in research in CB SCs and in the international registry of $\mathrm{CB}$ transplants. Thus, it brings together the European network of cord blood banks (NETCORD), the European Group for Blood and Marrow Transplantation (EBMT), the European Hematology Association (EHA) as well as the CB banks in Athens, Leiden, Madrid and Milan.

Eurocord has started an initiative called "On-line CME program in cord blood technology and transplantation", which provides scientific, technical and regulative information for healthcare. This program is available in several languages (www.eurocord-ed.org).

The Center for International Blood and Marrow Transplant Research (CIBMTR) is a private firm at the Medical College of Wisconsin Clinical Cancer Center in Milwaukee (Wisconsin, USA), which promotes research in hematopoietic cell transplantation and cellular therapy worldwide.

The Foundation for the Accreditation of Cellular Therapy (FACT) with headquarters at the University of Nebraska Medical Center (Omaha, NE; USA) deals with patient care and laboratory practice. The nonprofit corporation was co-founded by the International Society for Cellular Therapy (ISCT) and the American Society of Blood and Marrow Transplantation (ASBMT) for the inspection and accreditation in the field of cellular therapy.
Likewise, the National Marrow Donor Program (NMDP) is a nonprofit organization based in Minneapolis (Minnesota, USA) that registers volunteer donors of bone marrow and CB. As of February 2012, the NMDP had facilitated more than 50,000 transplants worldwide (wikipedia.org).

Without doubt, CB can be collected safely for both, mother and child, after delivery.

It was learned that one umbilical cord contains an adequate number of SCs for a successful engraftment in low body weight patients (up to $40 \mathrm{~kg}$ ) to reconstitute their immune system. CB SCs are highly prolific; they can be used for transplants to patients affected by onco-hematologic and genetic diseases. The criteria for isolation and conservation are now well defined and internationally shared.

\section{PARAMETERS OF UMBILICAL CORD BLOOD}

Ian K. McNiece and Elizabeth J. Shpall were the first to show that $\mathrm{CB}$ shares similar cell types with bone marrow and peripheral blood. After growth stimulation, e.g. with the Granulocyte Colony Stimulating Factor, undifferentiated and slightly differentiated SCs were obtained (McNiece and Shpall, 2009). Such differentiated SCs and functional auxiliary cells are essential for SC engraftment. However, the total number of cells, comprising hematopoietic progenitors, collected from one umbilical cord, is significantly lower (roughly $5 \times 10^{6}$ ) than from donated bone marrow or from peripheral blood after mobilization (roughly $1 \times 10^{8}$ cells). Until few years ago, only little children (up to $40 \mathrm{~kg}$ ) could be transplanted with SCs obtained from CB. A stringent code for quality and security determines the amount of a $\mathrm{CB}$ transplant. Donated $\mathrm{CB}$ must contain per $\mathrm{kg}$ recipient's body weight at least $3 \times 10^{7}$ nucleated cells or more than $2 \times 10^{5}$ specific cells with CD34+ phenotype. In each case, two disparities are tolerable between donor and recipient in their Human Leukocyte Antigen (HLA) systems. It is important to remember that in SSC transplants, donor and recipient must have a perfect HLA compatibility. For genetic diseases with a higher rejection risk, $\mathrm{CB}$ transplant requires, at least, $3 \times 10^{7}$ cells (as suggested by Gluckman's latest paper, even though this number will likely change in a few years).

Some specialized hospitals, including MD Anderson Cancer Center (Texas, USA) and Fondazione IRCCS Policlinico San Matteo (Pavia, Italy), try to overcome these stringent limits. Their novel schedule administers two similar, but not identical CB doses, which provide patients with a lot of cells during initial transplant phases. The donated cell populations compete in proliferation, and the most suitable prevail. Preliminary data show this approach promises to expand the possibility for transplantation in older and consequently heavier patients.

Impressive data certify $\mathrm{CB}$ as an important source of SCs for transplants. A matching dose with checked good quality can be identified in CB banks within 15-20 days. In contrast, 6 months are usually required to find in the donors' network a compatible sample of bone marrow.

A CIBMTR survey over the last 12 years estimated that $20 \%$ of transplants in young patients (under $20 \mathrm{yr}$ ) had been performed using SCs derived from CB. In Japan, 8,000 transplants from unrelated donors have used SCs derived from CB. This figure represents $50 \%$ of transplantations.

Data obtained from 233 European and 196 international transplant units through 1988-2008 showed intriguing results 
for treatment of genetic diseases or leukemia. No substantial differences were found between the treatments with SCs from traditional sources or with SCs from CB, neither in engraftment ability nor in long-term survival. Preliminary transplant data from adult high-weight patients indicated SCs from CB and from classical sources equally good.

CB application may meet limitations sometimes, when an engraftment fails because of too few SCs in a sample. Another risk comes from the potential transmission of genetic abnormalities like malignant mutations occurring in young SCs.

In the last ten years, however, the cellular composition of $\mathrm{CB}$ has became more important. Researchers are looking for differences in cells that populate a given sample of CB.

\section{BANKS AND RECIPIENTS OF UMBILICAL CORD BLOOD}

Three aims for CB conservation may be discriminated according to the donor's intention: allogenic donation, dedicated donation and autologous donation.

Regarding the allogenic donation, $\mathrm{CB}$ is given to a specialized bank for anybody who is compatible and needs a hematopoietic SC transplant. Indeed, CB donation is a solidarity act regulated by law in Italy. Lombardy was the first to set up a regional bank for conservation, analysis, characterization and distribution of CB. Nowadays, Italy has 18 public banks and 200 birth centers able to collect up to 20,000 CB samples (www.trapianti.ministerosalute.it). The banks in Milan and in Pavia alone dispose of 7,000 and 4,000 CB doses, respectively. Currently, a total of some 300,000 CB doses are available around the world, where New York, Paris, Barcelona, Dusseldorf and London have the largest collection banks. Theoretically, a bank of 50,000 CB units is able to meet the transplants needs of a country as large as the U.K.

The challenge in the coming years is to collect and characterize $\mathrm{CB}$ with very high quality to meet regional and international requirements prescribed by FACT-NETCORD and JACIE (Joint Accreditation Committee-ISCT) and to achieve certifications by ISO (International Organization for Standardization) and EFI (European Federation of Immunogenetics). At the international level, only 16 banks got the prestigious international FACT accreditation and two of them are in Italy (Milan and Pavia).

The dedicated donation means that a child's sibling will get the CB infusion. In Italy, this procedure is restricted to families with high transmission risk of genetic diseases that can be treated with CB SCs transplant. CB conservation for this kind of use must be authorized by the hospital's expert committee.

The third intention is autologous conservation when CB of a newborn is determined for the exclusive use in favor of this child. The scientific community is against such conservation, because there are no established indications and protocols for this very special kind of transplant. Besides, CB SCs may carry genetic mutations. In Italy, the law prohibits $\mathrm{CB}$ conservation in private institutions and does not allow any advertising for autologous conservation; however, a specific authorization may be issued by the Ministry of Health if autologous CB has to be conserved abroad. In this last case, parents expecting a baby must choose the hospital to which the CB delivery will take place and must afford the costs without any administrative help. It is worth noting that the most respected scientific societies, like the medical institutions of the European
Union, the Council of Europe and particular scientific authorities (French, Italian and others) take autologous conservation - rare cases excepted - for therapeutic futility. Unfortunately, some marketing campaigns try to convince VIP mothers from show business or sports to conserve their baby's CB. They appeal to emotions and spread naïve statements that autologous conservation is a "little treasure" for a child's future. This creates false expectations in the society, especially when famous actresses declare to conserve the CB of their babies in private banks. It must be remembered that if not counteracted this situation produces, just for Italy, the actual figure of nearly 10,000 CB units exported to private banks (Switzerland, San Marino).

This manifests an attitude directed against young patients who actually are waiting for transplants. Only allogenic CB donations make SCs available for everyone without any distinction of ethnicity or wealth.

Nowadays a new method for the collection of the large amount of $\mathrm{CB}$ that is commonly thrown away is emerging: actually, only $25-30 \%$ of collected CB units are cryo-preserved (those with high level standards for clinical use and the correct qualitative and quantitative parameters established by European regulations). By increasing the number of $\mathrm{CB}$ units, it will be possible to provide therapeutic support for a great number of new patients in a very short time. This opportunity is quite relevant considering that CB contains a highly heterogeneous mixture of cells: in addition to the hematopoietic SC there are both mesenchymal SC (MSC) and endothelial progenitor cells. MSCs have different biological functions: they're assisting the engraftment of hematopoietic SCs, they have immunosuppressive proprieties and especially they are able to differentiate and reconstitute several tissues like bones, cartilage and muscles. Endothelial progenitor cells can be isolated and cultured in vitro and thanks to the high potentiality to grow and differentiate they are able to form new blood vessels. Researchers still have to understand how these pluripotent SCs are able to repair and/or generate ex novo different tissues, even though data regarding their ability of repairing cardiac tissue affected by ischemia are available (Khoo et al., 2008). Other new therapeutic advancements are emerging under the name of medical bio-engineering (Conconi et al., 2005; Bian and Bursac, 2009; Zhang and Webster, 2009).

These important findings lead to develop specific programs for the capillary collection of this exclusive biological material that could be used for many different therapeutic needs.

\section{STEM CELLS IN REGENERATIVE MEDICINE: CELLULAR THE- RAPIES}

The possibility to substitute damaged or dead cells with new functional ones has shifted the focal point in medicine from traditional pharmacological and surgical methods to SC-based therapies. Indeed, "regenerative" medicine is rapidly evolving in research and application. The new approach comprises regeneration, repair and replacement of cells or tissue or organs with the aim to restore their impaired function.

Moreover, regenerative medicine could be useful for conditions where present therapies are unsatisfactory or not effective. The human body has an endogenous repair system, in which SCs play a fundamental role. In fact, SCs can be found in every tissue, even if the activation of the repair mechanism is not fully understood. The artificial SC 
application, however, faces problems associated with extensive in vitro cell expansion, as well as cell death after implantation (Vacanti, 2006). There are also difficulties with the biomaterials employed as carriers, and extensive cell manipulations are still expensive. Lastly, ethical and moral questions compete with clinical translation.

The Medical Research Council published "a strategy for UK regenerative medicine" in March 2012 (www.mrc.ac.uk/ index.htm). It presents clear objectives and a delivery plan how the increased understanding for SC biology can be converted into clinical practice. The strategy extends to the stimulation of the body's own repair systems, to SC transplantation and to the use of acellular products. Such practices of translational medicine, which should be mimicked by other countries, will benefit both patients and economy.

Very innovative are preliminary employments of differentiated ESCs, especially of nerve cells. On 23 January 2009, the Food and Drug Administration (FDA) approved a phase I multicentre clinical trial for transplantation of oligodendrocytes, normally present in brain and spinal cord. Eleven patients who sustained complete thoracic-level spinal cord injuries were treated with "GRNOPC1", a product by the Geron Corporation (Menlo Park, California, USA). This was a suspension of oligodendrocyte progenitor cells derived from human ESCs, which had shown an amazing capacity to remyelinate and to stimulate nerve growth in preclinical studies. Geron estimated that these SCs need several months to replicate and to determine that the treatment was successful or not. Unfortunately, the trial was put on hold in August 2009 and then continued to 30 July 2010. Finally, in November 2011, Geron announced it would abandon SC research for financial reasons, but would continue monitoring the patients. Hopefully, this anecdotal trial will become routine soon for the patients sake. A good sign comes from the FDA decision to unlock another trial, focused on the Lou Gehrig's disease, which is the most common form of motor neuron diseases. The occasionally interrupted project is run by Neuralstem (Rockville, Maryland, USA).

To complete the scenario, it is important to note that regenerative medicine disposes already of several admitted SC applications. The biological reagents, the SCs, are available and ready for use. Some approaches apply a patient's own SCs, e.g. with defects in bone growth. Autologous SCs, either circulating ones or those from certain histological niches, can be induced to move towards the area in need of repair.

Other approaches produce large quantities of differentiated cells in vitro thanks to an innovative culturing technique. The "3-D suspension culture system" is a reliable alternative to the adherent static conditions in dishes: SCs are stirred in suspension bioreactors containing molecules of variable composition (Fluri et al., 2012; Shafa et al., 2012). Thus, cell differentiation can be triggered to form a variety of tissues: renal epithelium, lung or liver constituents, cardiomyocytes, dopaminergic neurons, motor neurons, bone cells, etc. High yields of differentiated cells are useful in tissue engineering to obtain three-dimensional, transplantable constructs. The process uses biopolymer "skeletons" to produce the required "organs". Basic research is testing this technique by targeted experiments on animal models in the pursuit of ambitious goals. For example, human germinal cells, sperm and oocytes, are to be created from triggered SCs with the help of pliable biomaterials as "skeleton" using nude mice as intermediate hosts.

Research into organ cultivation is underway in several countries and covers the whole spectrum of tissue defects. The efforts aim at repair the nervous system after spinal injuries and neurodegeneration, the cardiovascular system with necrotic areas after heart failure or the substitution of blood vessels. The production of muscles, articular cartilage, collagen type I for skeletal diseases, tendons and ligaments is intentional. The endocrine system is aimed at by treating diabetes mellitus type I. Attempts to grow teeth and the heart are in early stages of development. To date, successful cultivation of transplantable organs is limited to the bladder (Atala, 2011).

STEM CELLS IN REGENERATIVE MEDICINE: TARGETED DISEASES

The ongoing trials with SC based treatments span nowadays some diseases that find therapeutic relief already. Despite being still in an experimental phase, the new treatments may be approved in as little as five years. Three diseases, diabetes, Parkinson's disease and heart necrosis, are shown as examples.

Diabetes mellitus type I. The treatment of this disease has seen great advancement from the transplantation of pancreatic islets. Expectations come from the ability to culture SCs and to differentiate them in pancreatic cells. However, a method would be most innovative, which could obtain in vivo genetic reprogramming of differentiated exocrine pancreatic cells into endocrine $\beta$-cells. This strategy was realized in adult mice through the expression of Pdx1, Neurog3 and Mafa, which are key genes in $ß$-cells (Zhou et al., 2008). Thus, it was possible to turn exocrine cells into cells that are actually similar in morphology, size and ultra structure to B-cells. Moreover, these cells lowered hyperglycemic levels thanks to the production of insulin.

Parkinson's disease: The treatment of Parkinson's aims to compensate for the lost neurons with new and efficient dopaminergic cells. Experimental cellular therapy in animals showed already the feasibility of this approach (Nishimura et al., 2003). But from clinical trials on this illness, a timeconsuming controversy came about.

The first double-blind study transplanted human embryonic dopamine neurons in 40 cases with severe Parkinson's disease. The transplants survived, and some clinical benefit was found in younger, but not in older patients (Freed et al., 2001). However, an immediate meta-analysis applied the Unified Parkinson's Disease Rating Scale (UPDRS) to monitor disease progression in the 40 patients above (Isacson et al., 2001). It derived that Freed and colleagues had not correctly performed data analysis.

Then, more than 400 patients have been treated and rescued from the typical Parkinson symptoms (Lindvall and Hagell, 2002; Linazasoro, 2003; Lindvall and Bjorklund, 2004).

Scepticism arose because the primary end points (relief of the symptoms) did not match in these trials, even though the tomographic evidence showed the presence of active dopaminergic neurons in the midbrain of the treated patients. 
For a recent update of the dopaminergic neurons production for Parkinson's therapy, see Lindvall (2012).

Myocardial infarction. Annually, nearly half million cases of myocardial infarction occur in the USA. Almost sixty million people bear cardiovascular diseases worldwide, among them eight million in Italy. These numbers indicate a pressing reality to provide a systematic amelioration for a panoply of diseases with a common denominator, the loss of cardiomyocytes. Ideally, the injured heart functions will be restored by recruitment of progenitor cells in vivo and in loco. But regenerative medicine meets a bottleneck in cardiovascular complaints due to the lack of significant regenerative capacity of the mammalian heart. Hoped-for future, a viable source of SCs or progenitor cells of cardiomyocytes will be identified to overcome these difficulties.

Recent findings showed a resident source of SCs in mice, which possess the potential to contribute bona fide terminally differentiated cardiomyocytes after cardiac infarction (Smart et al., 2011). In addition, the possibility of a direct reprogramming of fibroblasts into cardiomyocytes is contributing to the optimistic view we are getting (Efe et al., 2011). Till now however, we remain with first transplantation trials using autologous bone-marrow derived SCs (BMSCs).

Martin-Rendon and co-workers at the Stem Cell Research Laboratory of John Radcliffe Hospital (Headington, Oxford, UK) reviewed on clinical evidence the safety and efficacy of BMSC transplantation in acute myocardial infarction (AMI; Martin-Rendon et al., 2008). They evaluated thirteen trials of BMSC treatment for AMI with a total of 811 participants. Accordingly, SC therapy had improved left ventricular ejection by $2.99 \%$ and had reduced the area of myocardial lesion by $3.51 \%$. Better results occurred when BMSCs had been infused within seven days following AMI and when the administered dose was higher than $10^{8}$ BMSCs. The latter figure and the general outcome were confirmed in further meta-analyses now including thirty-three trials with 1,765 participants (Clifford et al., 2012).

\section{ACKNOWLEDGEMENTS}

We deeply thank Dr. Helmut Zacharias for the time spent to critically read a preliminary version of the manuscript and for long discussions that definitely improved the paper significantly. The critical reading of a final version of the manuscript by Prof. Raul Fernandez Donoso (University of Chile) is warmly acknowledged.

This work was supported by grants "Ricerca finalizzata, Ministero della Salute (bando giovani ricercatori - anno 2009): Renal-committed embryonic stem cells to promote kidney regeneration (cod. GR-2009-1547415)" to MM and CAR.

\section{BIBLIOGRAPHY}

ATALA A (2011) Tissue engineering of human bladder. Br Med Bull. 97:81104.

BIAN W, BURSAC N (2009) Engineered skeletal muscle tissue networks with controllable architecture. Biomaterials 30:1401-1412.

BYRNE J (2011) Global transcriptional analysis of oocyte-based and factor-based nuclear reprogramming in the nonhuman primate. Cell Reprogram 13:1-9.

CAIRNS J (1975) Mutation selection and the natural history of cancer. Nature 255:197-200.
CAIRNS J (2002) Somatic stem cells and the kinetics of mutagenesis and carcinogenesis. Proc Natl Acad Sci USA 99:10567-10570.

CAIRNS J (2006) Cancer and the immortal strand hypothesis. Genetics 174:1069-1072.

CHEN CZ, LI L, LODISH HF, BARTEL DP (2004) MicroRNAs modulate hematopoietic lineage differentiation. Science 303:83-86.

CLIFFORD DM, FISHER SA, BRUNSKILL SJ, DOREE C, MATHUR A, CLARKE MJ, WATT SM, MARTIN-RENDON E (2012) Long-term effects of autologous bone marrow stem cell treatment in acute myocardial infarction: factors that may influence outcomes. PLoS One 7(5):e37373. Epub May 24.

CONCONI MT, DE COPPI P, DI LIDDO R, VIGOLO S, ZANON GF PARNIGOTTO PP, NUSSDORFER GG (2005) Tracheal matrices, obtained by a detergent-enzymatic method, support in vitro the adhesion of chondrocytes and tracheal epithelial cells. Transpl Internat 18:727-734.

CREGAN, MD, FAN Y, APPELBEE AJ, BROWN ML, KLOPCIC B, KOPPEN JA, MITOULAS LR, PIPER KME, CHOOLANI MA, CHONG YS, HARTMANN PE (2007) Identification of nestin-positive putative mammary stem cells in human breast milk. Cell Tissue Res 329:129-136.

DE COPPI P, BARTSCH G, SIDDIQUI M, MINHAJ M, XU T, SANTOS CC, PERIN L, MOSTOSLAVSKY G, SERRE AC, SNYDER EY, YOO JJ, FURTH ME, SOKER S, ATALA A (2007) Isolation of amniotic stem cell lines with potential for therapy. Nature Biotech 25:100-106.

DINSER R (2001) Der Beitrag Artur Pappenheims zur Hämatologie um die Jahrhundertwende. Thesis, Bochum University, pp 178.

DURAND EM, ZON LI (2012) The blood balance. Nature 468:644-645.

EFE JA, HILCOVE S, KIM J, ZHOU H, OUYANG K, WANG G, CHEN J, DING S (2011) Conversion of mouse fibroblasts into cardiomyocytes using a direct reprogramming strategy. Nat Cell Biol 13:215-222.

ESCOBAR M, NICOLAS P, SANGAR F, LAURENT-CHABALIER S, CLAIR P, JOUBERT D, JAY P, LEGRAVEREND C (2011) Intestinal epithelial stem cells do not protect their genome by asymmetric chromosome segregation. Nat Comm 2:258-266.

EVANS M, KAUFMAN M (1981) Establishment in culture of pluripotent cells from mouse embryos. Nature 292:154-156.

FLURI DA, TONGE PD, SONG H, BAPTISTA RP, SHUKLA SN, CLARKE G, NAGY A, ZANDSTRA PW (2012) Derivation, expansion and differentiation of induced pluripotent stem cells in continuous suspension cultures. Nat Methods 9:509-516.

FREED CR, GREENE PE, BREEZE RE, TSAI WY, DUMOUCHEL W, KAO R, DILLON S, WINFIELD H, CULVER S, TROJANOVSKI JQ, EIDELBERG D, FAHN S (2001) Transplantation of embryonic dopamine neurons for severe Parkinson's disease. New Engl J Med 344:710-719.

FULLER MT, SORADLING AC (2007) Male and female Drosophila germline stem cells: two versions of immortality. Science 316: 402-404.

GIORGETTI A, MONTSERRAT N, AASEN T, GONZALES F, RODRÍGUEZPIZA I, VASSENA R, RAYA A, BOUE S, BARRERO JM, ARAN CORBELLA B, TORRABADELLA M, VEIGA A, BELMONTE JCI (2009) Generation of induced pluripotent stem cells from human cord blood using OCT4 and SOX2. Cell Stem Cell 5:353-357.

GLUCKMAN E, BROXMEYER HA, AUERBACH AD, FRIEDMAN HS, DOUGLAS GW, DEVERGIE A, ESPEROU H, THIERRY D, SOCIE G, LEHN P, COOPER S, ENGLISH D, KURTZBERG J, BARD J, BOYSE EA (1989) Hematopoietic reconstitution in a patient with Fanconi's anemia by means of umbilical-cord blood from an HLA-identical sibling. N Engl J Med 321:1174-1178.

GRAF T, ENVER T (2009) Forcing cells to change lineages. Nature 462:587594.

GRONTHOS SM, MANKANI J, BRAHIM P, ROBEY G, SHI S (2000) Postnatal human dental pulp stem cells (DPSCs) in vitro and in vivo. Proc Natl Acad Sci USA 97:13625-13630.

HAYDEN EC (2011) The growing pains of pluripotency. Nature 473:272-274.

HEMBERGER M, DEAN W, REIK W (2009) Epigenetic dynamics of stem cells and cell lineage commitment: digging Waddington's canal. Nat Rev Mol Cell Biol 10:526-537.

ISACSON O, BJORKLUND L, PERNAUTE RS (2001) Parkinson's disease: interpretations of transplantation study are erroneous. Nat Neuroscience 4:553.

JONES DL AND WAGERS AJ (2008) No place like home: anatomy and function of the stem cell niche. Nat Rev Mol Cell Biol. 9:11-21.

JULLIEN J, PASQUE V, HALLEY-STOTT RP, MIYAMOTO K, GURDON JB (2011) Mechanisms of nuclear reprogramming by eggs and oocytes: a deterministic process? Nat Rev Mol Cell Biol 12:453-459.

KIGER AA, JONES DL, SCHULZ C, ROGERS MB, FULLER MT (2001) Stem cell self-renewal specified by JAK-STAT activation in response to a support cell cue. Science 294:2542-2545. 
KHOO CP, POZZILLI P, ALISON MR (2008) Endothelial progenitor cells and their potential therapeutic applications. Regen Med 3:863-876.

KIMBLE JE, WHITE JG (1981) On the control of germ cell development in Caenorhabditis elegans. Dev Biol 81:208-219.

KIM JB, GREBER B, ARAÚZO-BRAVO MJ, MEYER J, PARK KI, ZAEHRES H, SCHÖLER HR (2009) Direct reprogramming of human neural stem cells by OCT4. http:/ / www.ncbi.nlm.nih.gov/ pubmed / 19718018 Nature 461:649-643.

KLUIVER J, KROESEN BJ, POPPEMA S, VAN DEN BERG A (2006) The role of microRNAs in normal hematopoiesis and hematopoietic malignancies. Leukemia 20: 1931-1936.

KNOBLICH JA (2008) Mechanisms of asymmetric stem cell division. Cell 132:583-597.

LEBLOND CP, CLERMONT Y (1952) Definition of the stages of the cycle of the seminiferous epithelium in the rat. Annals NY Acad Sci 55:548.

LI W, WEI W, ZHU S, ZHU J, SHI Y, LIN T, HAO E, HAYEK A, DENG H, DING S (2009) Generation of rat and human induced pluripotent stem cells by combining genetic reprogramming and chemical inhibitors. Cell Stem Cell 4:16-19.

LINAZASORO G (2003). Malignant syndrome in Parkinson's disease. Parkinsonism Relat Disord 10:115-116.

LINDVALL O (2012) Dopaminergic neurons for Parkinson's therapy. Nat Biotechnology 30:56-58.

LINDVALL O, BJORKLUND A (2004). Cell therapy in Parkinson's disease. NeuroRx 4:382-393.

LINDVALL O, HAGELL P (2002). Role of cell therapy in Parkinson disease. Neurosurg Focus 13:e2.

MAEHLE AH ( 2011) Ambiguous cells: the emergence of the stem cell. Notes Rec R Soc doi: 10.1098/rsnr.2011.0023.

MARTIN G (1981) Isolation of a pluripotent cell line from early mouse embryos cultured in medium conditioned by teratocarcinoma stem cells. Proc Natl Acad Sci USA 78:7634-7638.

MARTIN-RENDON E, BRUNSKILL SJ, HYDE CJ, STANWORTH SJ, MATHUR A, WATT SM (2008) Autologous bone marrow stem cells to treat acute myocardial infarction: a systematic review. Eur Heart J 29:1807-1818.

MCNIECE IK, SHPALL EJ (2009) Ex vivo expansion of cord blood. In "Frontiers of Cord Blood Science" Bhattacharya N and Stubblefield P (eds). Springer, London, pp 91-96.

MONTI M, REDI CA (2011a) Stem cells. In "Biotechnology in surgery" Barbarisi A (ed) Springer Italia, pp 131-149.

MONTI M, REDI CA (2011b) The biopolitics of frozen embryos. Int J Dev Biol 55:243-247.

MORRISON SJ, SPRADLING AC (2008) Stem cells and niches: mechanisms that promote stem cell maintenance throughout life. Cell 132: 598-611.

NERI T, MONTI M, REBUZZINI P, MERICO V, GARAGNA S, REDI CA ZUCCOTTI M (2007) Mouse fibroblasts are reprogrammed to Oct-4 and Rex-1 gene expression and alkaline phosphatase activity by embryonic stem cell extracts. Cloning Stem Cells 9:394-406.

NISHIMURA F, YOSHIKAWA M, KANDA S, NONAKA M, YOKOTA H, SHIROI A, NAKASE H, HIRABAYASI H, OUJI Y, BIRUMACHI J, ISHIZAKA S, SAKAKI T (2003) Potential use of embryonic stem cells for the treatment of mouse parkinsonian models: improved behaviour by transplantation of in vitro differentiated dopaminergic neurons from embryonic stem cells. Stem cells 21:171-180.

PALERMO A, DOYONNAS R, BHUTANI N, POMERANTZ J, ALKAN O, BLAU HM (2009) Nuclear reprogramming in heterokaryons is rapid, extensive, and bidirectional. FASEB J 23:1431-1440.
PFEIFFER MJ, SIATKOWSKI M, PAUDEL Y, BALBACH ST, BAEUMER N, CROSETTO N, DREXLER HCA, FUELLEN G, BOIANI M (2011) Proteomic analysis of mouse oocytes reveals 28 candidate factors of the "reprogrammome". J Proteome Res 10:2140-2153.

RAMALHO-SANTOS M, WILLENBRING H (2007) On the Origin of the term "stem cell". Cell Stem Cell 1:35-38.

RANDO TA (2007) The immortal strand hypothesis: Segregation and reconstruction. Cell 129:1239-1243.

REYA T, CLEVERS H (2005) Wnt signalling in stem cells and cancer. Nature 434:843-50.

SCHERES B (2007) Stem-cell niches: nursery rhymes across kingdoms. Nat Rev Mol Cell Biol 8:345-354.

SCHOFIELD R (1978) The relationship between the spleen colony-forming cell and the haemopoietic stem cell. Blood Cells 4:7-25.

SHAFA M, DAY B, YAMASHITA A, MENG G, LIU S, KRAWETZ R, RANCOURT D (2012) Derivation of iPSCs in stirred suspension bioreactors. Nat Methods 9:465-466.

SHAMBLOTT MJ, AXELMAN J, WANG S, BUGG EM, LITTLEFIELD JW, DONOVAN PJ, BLUMENTHAL PD, HUGGINS GR, GEARHART JD (1998) Derivation of pluripotent stem cells from cultured human primordial germ cells. Proc Natl Acad Sci USA 95:13726-13731.

SMART N, BOLLINI S, DUBÉ KN, VIEIRA JM, ZHOU B, DAVIDSON S, YELLON D, RIEGLER J, PRICE AN, LYTHGOE MF, PU WT, RILEY PR (2011) De novo cardiomyocytes from within the activated adult heart after injury. Nature 474:640-644

SOLTER D (2002). Cloning v. clowning. Genes Dev 16:1163-1166.

STADTFELD M, HOCHEDLINGER K (2010) Induced pluripotency: history, mechanisms, and applications. Genes Dev 24:2239-2263.

TAKAHASHI K, YAMANAKA S (2006) Induction of pluripotent stem cells from mouse embryonic and adult fibroblast cultures by defined factors. Cell 126:663-676.

THOMSON J, ITSKOVITZ-ELDOR J, SHAPIRO S, WAKNITZ M, SWIERGIEL J, MARSHALL V, JONES J (1998) Embryonic stem cell lines derived from human blastocysts. Science 282:1145-1147.

TULINA N, MATUNIS E (2001) Control of stem cell self-renewal in Drosophila spermatogenesis by JAK-STAT signaling. Science 294:25462549

VACANTI CA (2006). The history of tissue engineering. J Cell Mol Med 10:569-576.

WAKAYAMA T, PERRY AC, ZUCCOTTI M, JOHNSON KR, YANAGIMACHI R (1998) Full-term development of mice from enucleated oocytes injected with cumulus cell nuclei. Nature 394:369374.

WILMUT I, SCHNIEKE AE, MCWHIR J, KIND AJ, CAMPBELL KH (1997) Viable offspring derived from fetal and adult mammalian cells. Nature 385:810-813.

YAMANAKA S. (2009). Elite and stochastic models for induced pluripotent stem cell generation. Nature 460:49-52.

ZHANG L, WEBSTER TJ (2009) Nanotechnology and nanomaterials: promises for improved tissue regeneration. Nanotoday 4:66-80.

ZHOU Q, BROWN J, KANAREK A, RAJAGOPAL J, MELTON DA (2008) In vivo reprogramming of adult pancreatic exocrine cells to $\beta$-cells. Nature 455:627-632.

XU Y, SHI Y, DING S (2008) A chemical approach to stem-cell biology and regenerative medicine. Nature 453:338-344 